(2) Open Access Full Text Article

\title{
A randomized double-masked study to compare the ocular safety, tolerability, and efficacy of bromfenac $0.075 \%$ compared with vehicle in
} cataract surgery subjects

\author{
This article was published in the following Dove Press journal: \\ Clinical Ophthalmology \\ 21 November 2016 \\ Number of times this article has been viewed
}

\author{
Kamran Hosseini ${ }^{1}$ \\ Thomas Walters ${ }^{2}$ \\ Robert DaVanzo 3 \\ Richard L Lindstrom ${ }^{4}$ \\ 'InSite Vision Inc., Alameda, CA, ${ }^{2}$ Texan \\ Eye, Austin, TX, ${ }^{3}$ Cornerstone Health \\ Care, High Point, NC, ${ }^{4}$ Minnesota Eye \\ Consultants, Bloomington, MN, USA
}

Correspondence: Kamran Hosseini InSite Vision Inc., 965 Atlantic Avenue Alameda, CA 9450I, USA

Tel +I 5 I0 747 I264

Email kamran.hosseini@sunpharma.com
Purpose: The aim of this study was to evaluate the safety, tolerability, and efficacy of a low-dose version of bromfenac $0.075 \%$ in DuraSite ${ }^{\circledR}$ (bromfenac $0.075 \%$ ) compared with DuraSite ${ }^{\circledR}$ vehicle (vehicle) alone for the treatment of postoperative inflammation and ocular pain after cataract surgery.

Methods: A multicenter, double-masked, vehicle-controlled, parallel-group clinical trial of 240 subjects randomized in a $2: 1$ ratio to bromfenac $0.075 \%$ or vehicle was conducted. Subjects were dosed BID beginning 1 day before the cataract surgery, the day of surgery, and 14 days after surgery. A slit lamp biomicroscopy examination was performed to evaluate the signs of inflammation, including anterior chamber cells (ACC) and anterior chamber flare (ACF). The primary efficacy variable was the proportion of subjects with an ACC grade of 0 at Day 15 . Secondary efficacy endpoints included the proportion of subjects who achieved a pain score of 0 at each postsurgical visual analog scale (VAS) assessment and the proportion of subjects with an ACF grade of 0 at Day 15.

Results: At Day 15, proportionally more subjects in the bromfenac $0.075 \%$ group than in the vehicle group had an ACC grade of $0(57.1 \%$ vs $18.8 \%$, respectively; $P<0.001)$. At each of the postsurgical time points (Days 1, 8, 15, and 29), proportionally more bromfenac $0.075 \%$-treated subjects ( $76.8 \%, 90.5 \%, 92.9 \%$, and $85.1 \%$, respectively) had no pain (a VAS score of 0 ) compared with the vehicle-treated subjects $(48.2 \%, 38.8 \%, 42.4 \%$, and $47.1 \%$, respectively), and at each time point, these differences in proportions were statistically significant $(P<0.001)$. More subjects in the bromfenac $0.075 \%$ group had complete ACF resolution $(151 / 167 ; 90.4 \%)$ compared to those in the vehicle group $(54 / 85 ; 63.5 \%)$. There were no new safety signals reported.

Conclusion: Bromfenac $0.075 \%$ in DuraSite is safe, well tolerated, and effective at reducing inflammation and preventing pain associated with cataract surgery.

Keywords: bromfenac, cataract surgery, nonsteroidal anti-inflammatory drugs, cyclooxygenase inhibitor

\section{Introduction}

Cataract surgery - combining phacoemulsification and intraocular lens implantation - is the most frequently reimbursed operation among US Medicare patients, ${ }^{1,2}$ and $>3$ million procedures are performed yearly in the US. The ophthalmic community has generally accepted the use of topical agents during the cataract removal procedure for a variety of purposes. Typically, antibiotics are used for infection prophylaxis, postoperative steroids are used for cystoid macular edema (CME) and inflammation prevention, and 
nonsteroidal anti-inflammatory drugs (NSAIDs) are used for the postoperative control of ocular inflammation and discomfort prevention.

NSAIDs are well-known inhibitors of cyclooxygenase enzymes, ${ }^{3}$ and there are several NSAIDs approved for use in ophthalmic surgery in the US, such as bromfenac, diclofenac, ketorolac, nepafenac, and suprofen., ${ }^{4,5}$ This class of drugs is often used to reduce postoperative pain and to control inflammation during and after surgery. NSAIDs are also used for a variety of other purposes. ${ }^{6-8}$

Bromfenac is a potent cyclooxygenase inhibitor ${ }^{5}$ that has been studied and marketed since 2000 in Japan, since 2005 in the US, and since 2011 in Europe. ${ }^{4,9-12}$ DuraSite $^{\circledR}$ (Sun Pharma, Alameda, CA, USA) is a synthetic polymer of cross-linked polyacrylic acid, polycarbophil, that stabilizes small molecules, like the antibiotic azithromycin, in an aqueous matrix. Both clinical and nonclinical studies have shown DuraSite drug delivery system to be safe and nontoxic. ${ }^{13}$ DuraSite is commercially available in the US in two antibiotic formulations (one with $1 \%$ azithromycin and the other with $0.6 \%$ besifloxacin). The DuraSite technology has been used in a formulation of loteprednol gel as well.

This study was designed to evaluate the safety, tolerability, and efficacy of a low-dose version of bromfenac $0.075 \%$ in DuraSite (study drug) compared to DuraSite vehicle (vehicle) when dosed twice daily beginning 1 day prior to cataract surgery, the day of surgery, and then continuing for 14 days after surgery for the treatment of postoperative inflammation and ocular pain.

Results from this and earlier studies led to the US Food and Drug Administration (FDA) approval of bromfenac ophthalmic solution $0.075 \%$ in DuraSite (BromSite) in April 2016 for the treatment of postoperative inflammation and prevention of pain in patients undergoing cataract surgery. This approval is the first in the US to include prevention of pain; other NSAIDs are indicated for the treatment of inflammation and reduction of pain.

\section{Methods}

This study was a multicenter, randomized, double-masked, vehicle-controlled, parallel-group clinical trial designed to evaluate the ocular safety, tolerability, and efficacy of topical administration of bromfenac $0.075 \%$ compared to vehicle when dosed BID beginning 1 day prior to cataract surgery, the day of surgery, and then continuing for 14 days after surgery.

Six visits were required for full study participation, including the dosing phase and the evaluation phase. Subjects were to exit the study on Visit 6 (Day 29).

A diagram of the study design is provided in Figure 1.

\section{Study design}

Two-hundred forty subjects were planned for enrollment and randomized in a 2:1 ratio to either bromfenac $0.075 \%$ or vehicle; this number of subjects was expected to provide sufficient power to detect a meaningful treatment-related difference for the primary efficacy analysis.

\section{Statistical analysis}

The primary analysis of the primary efficacy endpoint was based on the intent-to-treat (ITT) population and last observation carried forward (LOCF) data. The difference between the bromfenac $0.075 \%$ and vehicle treatment groups in the proportion of subjects with an anterior chamber cells (ACC) grade of 0 by Day 15 was tested using a chi-square test. A 95\% confidence interval for the difference of the proportion was constructed based on a chi-square distribution.

The secondary efficacy endpoint was the proportion of subjects who achieved a pain score of 0 at each postsurgical visual analog scale (VAS) assessment. Analysis of the secondary efficacy endpoint was based on the ITT population and LOCF imputations.

Unless otherwise stated, any statistical tests performed used two-sided tests at the 5\% significance level. All analyses and summaries were performed using the SAS Software Version 9.1 or later (SAS Institute, Cary, NC, USA).

\section{Inclusion/exclusion criteria}

Key inclusion criteria included subjects aged at least 18 years who were scheduled for unilateral cataract surgery, subjects with a best-corrected visual acuity (BCVA) of at least $+1.0 \log$ of the minimum angle of resolution $(\log M A R)$ (Snellen equivalent of 20/200) in the fellow eye (nonstudy eye), and subjects who had an intraocular pressure (IOP) of $>8 \mathrm{mmHg}$ and $\leq 22 \mathrm{mmHg}$ in the study eye.

Key exclusion criteria included subjects with a history of Fuchs' dystrophy, diabetic retinopathy, and/or previous

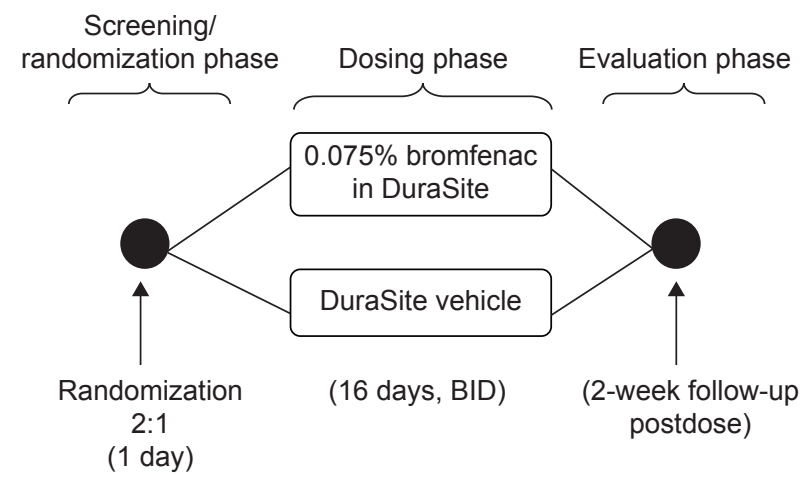

Figure I Study design. 
vitrectomy within the previous 2 years; iritis or scleritis, severe dry eye, or glaucoma surgery within the previous 2 years in the study eye; any active or chronic/recurrent ocular or systemic disease that was uncontrolled and likely to have affected wound healing (eg, diabetes mellitus, systemic connective tissue disease, severe atopic disease); intraocular inflammation (cells or flare in anterior chamber) or ocular pain $(>0)$ on the pain scale in either eye; and previous radial keratotomy, corneal transplant, or LASIK in the study eye within the last 2 years.

Protocol and informed consent form (ICF) for this study were reviewed and approved by an Institutional Review Board (IRB) (Quorum Review IRB, Seattle, WA, USA) registered with the US Department of Health and Human Services Office for Human Research Protections and with the FDA and provided to the contract research organization (CRO; Pharm-Olam International, Houston, TX, USA) before subjects were screened for entry. All patients provided written informed consent prior to any study procedures. The study is registered with ClinicalTrials.gov (ID: NCT01576952).

\section{Treatment administration}

Subjects were instructed to store bromfenac $0.075 \%$ at room temperature and to administer two doses on Day -1 in the study eye, one dose on Day 0 prior to cataract surgery, and one dose on the evening after surgery and to continue dosing BID at 12-hour intervals for 14 days after surgery. Subjects were given a dosing diary to record bromfenac $0.075 \%$ application dates and times. No other eye drops (eg, artificial tears) were to be administered for at least 1 hour after the bromfenac $0.075 \%$ dose. All other topical medications must have been administered at least 5 minutes before bromfenac $0.075 \%$.

Subjects were screened and enrolled at Visit 1 (Days -14 to -2 ); surgery was scheduled for Visit 2 (Day 0 ) at this time. Subjects were contacted by telephone on Day -2 to remind them of required dosing diary completion, dosing on Days -1 and 0 , as well as dosing for 14 days after cataract surgery in the study eye. Dosing with masked bromfenac $0.075 \%$ began on Day -1 . Subjects exited the study on Day 29 (Visit 6). At Visit 2 (Day 0 ), subjects were to undergo cataract surgery. Subsequent visits were required at Day 1 (Visit 3), Day 8 (Visit 4), and Day 15 (Visit 5, 12-48 hours after the last dose of study drug). Subjects were to attend a follow-up visit (Visit 6) on Day 29.

\section{Outcome measurements}

A slit lamp biomicroscopy examination was performed to evaluate the signs of inflammation including ACC, anterior chamber flare (ACF), chemosis, bulbar conjunctival injection, ciliary injection, corneal edema, keratic precipitates, and general health of the eye.

\section{$A C C$ and $A C F$}

The primary efficacy variable was the proportion of subjects with an ACC grade of 0 at Day 15. Subjects with an ACC grade $>0$ at Day 15 were not counted as responders. ACC were counted and graded according to Table 1. An analysis of the primary efficacy endpoint, proportion of subjects with an ACC grade of 0 at Day 15, was based on the modified ITT (mITT) population (subjects, who were randomized, underwent cataract surgery and received at least one dose of the study drug); the LOCF was used to impute missing data. The difference between treatment with bromfenac $0.075 \%$ and vehicle was tested using the chi-square test.

\section{Secondary outcomes and endpoints}

\section{Pain assessment}

Pain/discomfort and photophobia was assessed by the subject in the study eye using the VAS. The investigator or study staff turned the scale over and recorded the associated measurement $(0 \mathrm{~mm}=$ absent to $100 \mathrm{~mm}=$ maximum $)$.

One secondary efficacy endpoint was the proportion of subjects who achieved a pain score of 0 at each postsurgical VAS assessment. Analysis of the secondary efficacy endpoint was based on the mITT population; the LOCF method was used to impute missing data.

The proportion of subjects who achieved a pain score of 0 on the VAS at each postsurgical assessment was calculated for each treatment group. The difference in proportions between the treatment groups was tested using the chi-square test.

Table I Anterior chamber cell and flare grading

\begin{tabular}{lllll}
\hline Anterior chamber cells & & \multicolumn{2}{l}{ Anterior chamber flare } \\
\cline { 5 - 5 } Grade & Cell count & & Grade & Flare count \\
\hline 0 & 0 & 0 & None: no haze is detected \\
$\mathrm{I}$ & $\mathrm{I}-10$ & $\mathrm{I}$ & Mild: a faint haze is detected \\
2 & $\mathrm{II}-20$ & 2 & Moderate: haze is easy to detect, but iris details are not obscured \\
3 & $2 \mathrm{I}-50$ & 3 & Marked: haze is prominent, and iris details are somewhat obscured \\
4 & $>50$ & 4 & Severe: haze is dramatic, iris details are very obscured, and/or the aqueous is fibrinoid or plastic \\
\hline
\end{tabular}


Another secondary efficacy endpoint was the proportion of subjects with an ACF grade of 0 at Day 15. The proportion of subjects with an ACF grade of 0 at Day 15 was calculated for each treatment group. Analysis of the secondary efficacy endpoint was based on the mITT population; LOCF method was used to impute missing data. ACF was graded according to the parameters set forth in Table 1.

\section{Safety measurements and adverse event reporting}

Safety was assessed by the incidence of adverse events (AEs), BCVA, IOP, photophobia, biomicroscopy, ophthalmoscopic findings, and concomitant medication use.

Subjects were evaluated for adverse events at all study visits.

\section{Results}

\section{Study population}

Of the 279 subjects screened, 268 subjects were randomized as follows: 180 subjects to the bromfenac $0.075 \%$ group and 88 subjects to the vehicle group. Of the 268 randomized subjects, 12 subjects in the bromfenac $0.075 \%$ group and two in the vehicle group did not undergo cataract surgery for reasons not associated with the bromfenac $0.075 \%$ (but were included in the safety analysis); one additional subject in the vehicle group withdrew from the study before receiving any study drug. The mITT population, therefore, comprised 253 subjects or $94.4 \%$ of those randomized $(93.3 \%$, [168/180] in the bromfenac $0.075 \%$ group and $96.6 \%$, [85/88] in the vehicle group) (for subject disposition refer Table 2).

For the mITT population, the mean $( \pm$ standard deviation [SD]) age of the study subjects was $68.7( \pm 10.17)$ years and all subjects were aged between 24 and 87 years; these data were similar between treatment groups. The majority of

Table 2 Subject disposition

\begin{tabular}{|c|c|c|c|}
\hline Subject disposition & $\begin{array}{l}\text { Bromfenac } \\
0.075 \% \\
\text { group, n (\%) }\end{array}$ & $\begin{array}{l}\text { Vehicle } \\
\text { group, n (\%) }\end{array}$ & $\begin{array}{l}\text { Overall, } \\
\text { n (\%) }\end{array}$ \\
\hline Screened & & & 279 \\
\hline Randomized & 180 & 88 & 268 \\
\hline mITT population & $168(93.3)$ & $85(96.6)$ & $253(94.4)$ \\
\hline Safety population & 169 (93.9) & $85(96.6)$ & $254(94.8)$ \\
\hline Completed the study & 139 (77.2) & $33(37.5)$ & $172(64.2)$ \\
\hline \multicolumn{4}{|l|}{ Completion by study visit } \\
\hline Visit I (Days -14 to -2 ) & 180 & 88 & 279 \\
\hline Visit 2 (Day 0) & $168(93.3)$ & $86(97.7)$ & $254(94.8)$ \\
\hline Visit 3 (Day I) & $167(92.8)$ & $84(95.5)$ & $25 I(93.7)$ \\
\hline Visit 4 (Day 8) & $159(88.3)$ & $59(67.0)$ & $218(81.3)$ \\
\hline Visit 5 (Day I5) & $154(85.6)$ & $38(43.2)$ & $192(71.6)$ \\
\hline Visit 6 (Day 29) & 139 (77.2) & $33(37.5)$ & $172(64.2)$ \\
\hline
\end{tabular}

Abbreviation: $\mathrm{mITT}$, modified intent-to-treat. subjects were $\geq 65$ years $(71.5 \%[181 / 253])$. More than half of the subjects were female $(62.5 \%$ [158/253]). The majority of subjects were white $(85.4 \%$ [216/253]) and non-Hispanic (88.5\% [224/253]), and both treatment groups were relatively similar in regard to racial distribution. Almost half of the subjects (47.8\% [121/253]) had brown eyes, and almost onethird of the subjects (29.2\% [74/253]) had blue eyes overall and within each treatment group.

\section{Disposition}

Proportionally, almost three times as many subjects in the vehicle group $(55 / 88 ; 62.5 \%)$ discontinued the study compared to subjects in the bromfenac $0.075 \%$ group $(41 / 180 ; 22.8 \%)$.

Most of the subjects discontinuing the study in either group was due to the lack of efficacy, and there were approximately fivefold as many of these in the vehicle group $(39.8 \%$ $[35 / 88]$ ) compared to those in the bromfenac $0.075 \%$ group $(8.3 \%$ [15/180]). The next most frequent reason for study discontinuation was for AEs, and also more frequent in the vehicle group compared to that in the bromfenac $0.075 \%$ group (Table 3).

The proportion of study drug-treated subjects who received rescue medications was less compared to vehicletreated subjects $(4.8 \%$ [8/168] vs 36.5\% [31/85], respectively), and this difference was significant $(P<0.001)$.

\section{Efficacy}

There were proportionally more subjects in the bromfenac $0.075 \%$ group who had an ACC grade of 0 at Day 15 compared to those in the vehicle group $(57.1 \%$ vs $18.8 \%$, respectively; $P<0.001)$. Two subjects in the bromfenac $0.075 \%$ group (1.2\%) and three subjects in the vehicle group $(3.5 \%)$ received rescue therapy on Day 15 .

Table 3 Causes for study discontinuation

\begin{tabular}{|c|c|c|c|}
\hline $\begin{array}{l}\text { Discontinued subjects/ } \\
\text { causes }\end{array}$ & $\begin{array}{l}\text { Bromfenac } \\
0.075 \% \\
\text { group, n (\%) }\end{array}$ & $\begin{array}{l}\text { Vehicle } \\
\text { group, n (\%) }\end{array}$ & $\begin{array}{l}\text { Overall, } \\
\text { n (\%) }\end{array}$ \\
\hline Randomized & 180 & 88 & 268 \\
\hline Discontinued study early & $4 \mid(22.8)$ & $55(62.5)$ & $96(35.8)$ \\
\hline \multicolumn{4}{|l|}{ Reasons for discontinuation } \\
\hline Adverse event & $7(3.9)$ & $8(9.1)$ & $15(5.6)$ \\
\hline Investigator decision & $2(I .1)$ & $\mathrm{I}(\mathrm{I} . \mathrm{I})$ & $3(1.1)$ \\
\hline Lack of efficacy & $15(8.3)$ & $35(39.8)$ & $50(18.7)$ \\
\hline Subject withdrew consent & $8(4.4)$ & $\mathrm{I}(\mathrm{I} . \mathrm{I})$ & $9(3.4)$ \\
\hline Protocol deviation & $5(2.8)$ & $7(8.0)$ & $12(4.5)$ \\
\hline Others & $4(2.2)$ & $3(3.4)$ & $7(2.6)$ \\
\hline
\end{tabular}


The proportion of bromfenac $0.075 \%$-treated subjects with an ACF grade of 0 at Day $15(80.4 \% ; 135 / 168)$ was significantly greater compared to vehicle-treated subjects (35.3\%; $30 / 85)(P<0.001)$. Also, the proportion of subjects with an ACF grade $>0$ (grade $>0$, combined) was approximately threefold greater in the vehicle group $(51.8 \%$ [44/85]) compared to those in the bromfenac $0.075 \%$ group $(17.9 \%$ [30/168]).

Between-group differences in the mean ACC grades by study visit were of greater magnitude than those in the mean ACF grades, but a similar statistical trend was evident: minimal between-group differences at Day 1, but significantly lower mean ACF grade scores in the bromfenac $0.075 \%$ group than those in the vehicle group at each subsequent study visit (Days 8, 15, and 29).

The mean ACF grades decreased in both treatment groups from Day 8 to Day 29 and were consistently lower in the bromfenac $0.075 \%$ group than in the vehicle group across these study visits. At Day 1, ACF grades were similar in each group. However, at each of the subsequent study visits, the mean $( \pm \mathrm{SD}) \mathrm{ACF}$ grades were statistically significantly lower in the bromfenac $0.075 \%$ group than in the vehicle group $(0.4$ $[ \pm 0.67]$ vs $1.0[ \pm 0.92], 0.2[ \pm 0.59]$ vs $0.8[ \pm 0.96]$, and 0.2 $[ \pm 0.58]$ vs $0.7[ \pm 0.95]$ at Days 8,15 , and 29 , respectively; $P<0.001$ at each visit). The difference in proportions between the treatment groups was calculated using the chi-square test. On Days 1, 8, and 15, the proportion of subjects with an ACF grade of 0 without rescue therapy in the bromfenac $0.075 \%$ group $(\mathrm{n}=168)$ was $38(22.6 \%), 111(66.1 \%)$, and 135 (80.4\%), respectively. On Days 8 and 15, the difference between groups was significant $(P<0.001)$; on Day 1 , there was no significant difference ( $P=0.564)$. The difference in the time to achieve an ACF score of 0 was statistically significant $(P=0.030)$ in favor of bromfenac $0.075 \%$.

The proportion of subjects who had complete ACC resolution was $74.3 \%$ (124/167 subjects) in the bromfenac $0.075 \%$ group compared to $35.3 \%$ (30/85 subjects) in the vehicle group. The difference in the time to achieve resolution of ACC (resolution of ACC is defined as an ACC score of 0$)$ was statistically significant $(P=0.019)$ in favor of the bromfenac $0.075 \%$ group. Additionally, the probability of achieving ACC resolution was higher for the bromfenac $0.075 \%$ group at all time points.

\section{Pain scores}

At all time points, there was a significant difference between the bromfenac $0.075 \%$-treated group and the vehicle-treated group (Table 4).
Table 4 Proportion of subjects who achieved a pain score of 0 at each postsurgical VAS assessment (mITT population)

\begin{tabular}{|c|c|c|c|}
\hline $\begin{array}{l}\text { Visit } \\
\text { (study day) }\end{array}$ & $\begin{array}{l}\text { Bromfenac } 0.075 \% \\
\text { group }(n=168), n(\%)\end{array}$ & $\begin{array}{l}\text { Vehicle group } \\
(n=85), n(\%)\end{array}$ & $\begin{array}{l}\text { Adjusted } \\
\text { P-value }^{\mathrm{a}, \mathrm{b}}\end{array}$ \\
\hline Day I & $129(76.8)$ & $4 \mathrm{I}(48.2)$ & $<0.001$ \\
\hline Day 8 & I 52 (90.5) & $33(38.8)$ & $<0.001$ \\
\hline Day 15 & $156(92.9)$ & $37(42.4)$ & $<0.001$ \\
\hline Day 29 & $143(85.1)$ & 40 (47.I) & $<0.001$ \\
\hline
\end{tabular}

Notes: aP-values are from the chi-square test. ${ }^{b} P$-values were adjusted for multiple comparisons by Hochberg's step-up method.

Abbreviations: $\mathrm{mITT}$, modified intent-to-treat; VAS, visual analog scale.

A significantly greater proportion of subjects experienced no pain (defined as a VAS pain score of 0 at Day 1 and the next subsequent study visit) in the bromfenac $0.075 \%$ group than those in the vehicle group (Table 5).

\section{Safety}

There were no deaths, but one serious AE was observed during the study: one subject in the vehicle group developed severe endophthalmitis in the study eye (left eye) that was not considered study drug related and resolved with treatment. As a result, the subject was discontinued from the study.

Most treatment-emergent AEs (TEAEs) were of mild or moderate severity, and the proportions of subjects with these TEAEs were similar between treatment groups. More subjects in the vehicle group had severe TEAEs compared to

Table 5 Analysis of VAS pain scores by study visit (mITT population)

\begin{tabular}{|c|c|c|c|}
\hline Visit (study day) & $\begin{array}{l}\text { Bromfenac } 0.075 \% \\
\text { group }(n=168)\end{array}$ & $\begin{array}{l}\text { Vehicle group } \\
(n=85)\end{array}$ & $\begin{array}{l}\text { Adjusted } \\
\boldsymbol{P}^{\text {-value }}{ }^{\mathrm{a}, \mathrm{b}} \\
\end{array}$ \\
\hline Visit 3 (Day I) & & & $<0.001$ \\
\hline Mean (SD) (mm) & $4.3(11.49)$ & $15.4(2 \mid .81)$ & \\
\hline Median & 0.0 & 1.0 & \\
\hline $\begin{array}{l}\text { Minimum, } \\
\text { maximum }\end{array}$ & 0,63 & 0,80 & \\
\hline Visit 4 (Day 8) & & & $<0.001$ \\
\hline Mean (SD) (mm) & $2.2(9.11)$ & I8.I (24.59) & \\
\hline Median & 0.0 & 5.0 & \\
\hline $\begin{array}{l}\text { Minimum, } \\
\text { maximum }\end{array}$ & 0,60 & 0,85 & \\
\hline Visit 5 (Day I5) & & & $<0.001$ \\
\hline Mean (SD) (mm) & $1.9(9.47)$ & $16.9(24.22)$ & \\
\hline Median & 0.0 & 0.0 & \\
\hline $\begin{array}{l}\text { Minimum, } \\
\text { maximum }\end{array}$ & 0,70 & 0,85 & \\
\hline Visit 6 (Day 29) & & & $<0.001$ \\
\hline Mean (SD) (mm) & 3.4 (II.89) & I6.I (24.38) & \\
\hline Median & 0.0 & 0.0 & \\
\hline $\begin{array}{l}\text { Minimum, } \\
\text { maximum }\end{array}$ & 0,84 & 0,85 & \\
\hline
\end{tabular}

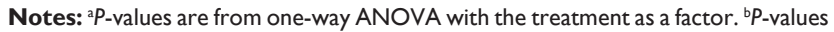
were adjusted for multiple comparisons by Hochberg's step-up method.

Abbreviations: ANOVA, analysis of variance; mITT, modified intent-to-treat; SD, standard deviation; VAS, visual analog scale. 
Table 6 Treatment emergent adverse events occurring in $\geq 5 \%$ in any treatment group

\begin{tabular}{|c|c|c|c|}
\hline $\begin{array}{l}\text { System } \\
\text { organ class } \\
\text { preferred term }\end{array}$ & $\begin{array}{l}\text { Bromfenac } 0.075 \% \\
\text { group }(n=169), n(\%)\end{array}$ & $\begin{array}{l}\text { Vehicle group } \\
(n=85), n(\%)\end{array}$ & $P$-value ${ }^{b}$ \\
\hline \multicolumn{4}{|l|}{ Eye disorders } \\
\hline Eye pain & $8(4.7)$ & II (I2.9) & 0.024 \\
\hline Iritis & $3(1.8)$ & $5(5.9)$ & 0.122 \\
\hline $\begin{array}{l}\text { Ocular } \\
\text { hypertension }\end{array}$ & $16(9.5)$ & $3(3.5)$ & 0.128 \\
\hline \multicolumn{4}{|c|}{ Nervous system disorders } \\
\hline Headache & $4(2.4)$ & $5(5.9)$ & 0.167 \\
\hline
\end{tabular}

Notes: alf an event occurred more than once in a subject, it was counted only once. 'PP-values are from a Fisher's exact test.

those in the bromfenac $0.075 \%$ group $(7.1 \%$ [6/85] vs $1.8 \%$ [3/169], respectively). Frequent AEs are shown in Table 6. One notable exception is the higher number and greater percentage of subjects in the bromfenac $0.075 \%$ group who had ocular hypertension $(n=16,9.5 \%)$ compared to those in the vehicle group $(n=3,3.5 \%)$, although these differences were not significant. All episodes of ocular hypertension occurred immediately after surgery and were not unexpected. None of the study investigators believe that an increase in ocular hypertension was a result of the bromfenac $0.075 \%$ or vehicle but was a result of the surgery itself. Changes in IOP from baseline were considered small and not clinically significant. By the following study visit (Day 1), all subjects had returned to their preoperative levels with or without any intervention. There was no evidence of a persistent or delayed elevation in IOP.

\section{Discussion}

During the postoperative period, ocular NSAIDs are prescribed to reduce the pain and inflammation associated with surgery. In this Phase III study, we found bromfenac $0.075 \%$ to be superior to vehicle in both primary and secondary endpoints (resolution of ACC and ACF grades at Day 15 [after 16 days of dosing] and prevention of postoperative pain). The bromfenac $0.075 \%$ group reported proportionally less pain early in the postsurgical period (Day 1) compared to the vehicle group.

The results of this study confirmed those of a previous Phase II study, where bromfenac $0.075 \%$ reduced inflammation better than the currently marketed versions of bromfenac in both once- and twice-daily formulations (InSite Vision Inc., data on file, 2012).

Our results add to the recent literature about the analgesic effects of bromfenac postcataract surgery. ${ }^{14-17}$ In particular, our study used bromfenac 0.075\% encased in DuraSite, and our efficacy results were similar to others published on bromfenac $0.07 \%$ without DuraSite. ${ }^{16,17}$ However, the bromfenac $0.075 \%$ in this trial was able to prevent pain, which has not been established with other formulations of bromfenac.

There has been discussion among clinicians about the perceived benefits of once-daily or twice-daily dosing. Advantages to twice-daily dosing include the retention of some of the active ingredient should a patient forget to instill one drop. There may be advantages with using DuraSite as the bioadhesive support matrix as well; clinical trials evaluating $1 \%$ azithromycin and $0.6 \%$ besifloxacin in DuraSite found a more convenient therapeutic course and better efficacy in the clinical resolution of bacterial conjunctivitis when DuraSite was used compared to either vehicle or other ophthalmic formulations. ${ }^{18-20}$ The use of DuraSite has been extensively researched and validated as an efficacious and safe method for ocular drug delivery. ${ }^{13,21-24}$

There are some limitations to this study. For instance, we limited the number of patients in the vehicle group as they were not allowed pain medication postoperatively in the study eye. (It is important to note, however, that analgesics were available as rescue medications regardless of assigned group.) This may, in fact, be a cause of the higher percentage of subjects in the placebo group who withdrew from the study. Although not all these patients were followed after withdrawal, the majority did so based on the lack of efficacy of the vehicle alone. Almost all the baseline subjects (93.7\%) completed the first postoperative visit (InSite Vision, Inc., data on file, 2015), indicating a willingness to continue study participation. While unlikely, it is possible that the ingredients in DuraSite (vehicle) may contribute to a patient's pain assessment. As both groups were dosed with DuraSite, we believe that there may have been a placebo effect in the vehicle group.

We have shown bromfenac $0.075 \%$ in DuraSite is safe, well tolerated, and effective at reducing inflammation and preventing pain associated with cataract surgery. As the number of cataract surgeries performed yearly continues to climb (estimated at 30 million globally by 2020), ${ }^{25}$ minimizing postoperative inflammation and preventing pain associated with cataract surgery will continue to be a concern for surgeons. ${ }^{26,27}$

\section{Disclosure}

Kamran Hosseini MD, $\mathrm{PhD}$, is an employee of InSite Vision Inc., a subsidiary of Sun Pharma. The remaining authors are consultants to InSite Vision Inc. The authors report no other conflicts of interest in this work. 


\section{References}

1. Williams A, Sloan FA, Lee PP. Longitudinal rates of cataract surgery. Arch Ophthalmol. 2006;124(9):1308-1314.

2. Smith RJ, McCannel CA, Gordon LK, et al. Evaluating teaching methods of cataract surgery: validation of an evaluation tool for assessing surgical technique of capsulorhexis. J Cataract Refract Surg. 2012;38(5):799-806.

3. Ahuja M, Dhake AS, Sharma SK, Majumdar DK. Topical ocular delivery of NSAIDs. AAPS J. 2008;10(2):229-241.

4. Cho H, Wolf KJ, Wolf EJ. Management of ocular inflammation and pain following cataract surgery: focus on bromfenac ophthalmic solution. Clin Ophthalmol. 2009;3:199-210.

5. Waterbury LD, Silliman D, Jolas T. Comparison of cyclooxygenase inhibitory activity and ocular anti-inflammatory effects of ketorolac tromethamine and bromfenac sodium. Curr Med Res Opin. 2006;22(6): $1133-1140$.

6. Donnenfeld ED, Donnenfeld A. Global experience with Xibrom (bromfenac ophthalmic solution) $0.09 \%$ : the first twice-daily ophthalmic nonsteroidal anti-inflammatory drug. Int Ophthalmol Clin. 2006;46(4):21-40.

7. Henderson BA, Gayton JL, Chandler SP, et al. Safety and efficacy of bromfenac ophthalmic solution (Bromday) dosed once daily for postoperative ocular inflammation and pain. Ophthalmology. 2011;118(11): 2120-2127.

8. Silverstein SM, Cable MG, Sadri E, et al. Once daily dosing of bromfenac ophthalmic solution $0.09 \%$ for postoperative ocular inflammation and pain. Curr Med Res Opin. 2011;27(9):1693-1703.

9. Bronuck [package insert]. Osaka, Japan: Senju Pharmaceutical Co.; 2009.

10. Xibrom [package insert]. Irvine, CA: ISTA Pharmaceuticals; 2010.

11. Bromday [package insert]. Irvine, CA: ISTA Pharmaceuticals; 2011.

12. Committee for Medicinal Products for Human Use (CHMP). Yellox Assessment Report. Report No.: EMA/431843/2011. May 19, 2011.

13. Bowman LM, Si E, Pang J, Archibald R, Friedlaender M. Development of a topical polymeric mucoadhesive ocular delivery system for azithromycin. J Ocul Pharmacol Ther. 2009;25(2):133-139.

14. Hoy SM. Bromfenac ophthalmic solution $0.07 \%$ : a review of its use after cataract surgery. Clin Drug Investig. 2015;35(8):525-529.

15. Wilson DJ, Schutte SM, Abel SR. Comparing the efficacy of ophthalmic NSAIDs in common indications: a literature review to support costeffective prescribing. Ann Pharmacother. 2015;49(6):727-734.

16. Walters TR, Goldberg DF, Peace JH, Gow JA; Bromfenac Ophthalmic Solution $0.07 \%$ Once Daily Study Group. Bromfenac ophthalmic solution $0.07 \%$ dosed once daily for cataract surgery: results of 2 randomized controlled trials. Ophthalmology. 2014;121(1):25-33.
17. Rajpal RK, Ross B, Rajpal SD, Hoang K. Bromfenac ophthalmic solution for the treatment of postoperative ocular pain and inflammation: safety, efficacy, and patient adherence. Patient Prefer Adherence. 2014;8: 925-931.

18. Abelson MB, Heller W, Shapiro AM, et al. Clinical cure of bacterial conjunctivitis with azithromycin $1 \%$ : vehicle-controlled, doublemasked clinical trial. Am J Ophthalmol. 2008;145(6):959-965.

19. Silverstein BE, Allaire C, Bateman KM, Gearinger LS, Morris TW, Comstock TL. Efficacy and tolerability of besifloxacin ophthalmic suspension $0.6 \%$ administered twice daily for 3 days in the treatment of bacterial conjunctivitis: a multicenter, randomized, double-masked, vehicle-controlled, parallel-group study in adults and children. Clin Ther. 2011;33(1):13-26.

20. DeLeon J, Silverstein BE, Allaire C, et al. Besifloxacin ophthalmic suspension $0.6 \%$ administered twice daily for 3 days in the treatment of bacterial conjunctivitis in adults and children. Clin Drug Investig. 2012;32(5):303-317.

21. Malhotra R, Gira J, Berdy GJ, Brusatti R. Safety of besifloxacin ophthalmic suspension $0.6 \%$ as a prophylactic antibiotic following routine cataract surgery: results of a prospective, parallel-group, investigator-masked study. Clin Ophthalmol. 2012;6:855-863.

22. Friedlaender MH, Protzko E. Clinical development of $1 \%$ azithromycin in DuraSite, a topical azalide anti-infective for ocular surface therapy. Clin Ophthalmol. 2007;1(1):3-10.

23. Shafiee A, Bowman LM, Hou E, Hosseini K. Ocular pharmacokinetics of bimatoprost formulated in DuraSite compared to bimatoprost $0.03 \%$ ophthalmic solution in pigmented rabbit eyes. Clin Ophthalmol. 2013; 7:1549-1556.

24. Opitz DL, Harthan JS. Review of azithromycin ophthalmic $1 \%$ solution (AzaSite (R)) for the treatment of ocular infections. Ophthalmol Eye Dis. 2012;4:1-14.

25. Congdon N, Vingerling JR, Klein BE, et al. Prevalence of cataract and pseudophakia/aphakia among adults in the United States. Arch Ophthalmol. 2004;122(4):487-494.

26. Henderson BA, Kim JY, Ament CS, Ferrufino-Ponce ZK, Grabowska A, Cremers SL. Clinical pseudophakic cystoid macular edema. Risk factors for development and duration after treatment. J Cataract Refract Surg. 2007;33(9):1550-1558

27. Wittpenn JR, Silverstein S, Heier J, et al. A randomized, masked comparison of topical ketorolac $0.4 \%$ plus steroid vs steroid alone in low-risk cataract surgery patients. Am J Ophthalmol. 2008;146(4):554-560.
Clinical Ophthalmology

\section{Publish your work in this journal}

Clinical Ophthalmology is an international, peer-reviewed journal covering all subspecialties within ophthalmology. Key topics include: Optometry; Visual science; Pharmacology and drug therapy in eye diseases; Basic Sciences; Primary and Secondary eye care; Patient Safety and Quality of Care Improvements. This journal is indexed on Submit your manuscript here: http://www.dovepress.com/clinical-ophthalmology-journal

\section{Dovepress}

PubMed Central and CAS, and is the official journal of The Society of Clinical Ophthalmology (SCO). The manuscript management system is completely online and includes a very quick and fair peer-review system, which is all easy to use. Visit http://www.dovepress.com/ testimonials.php to read real quotes from published authors. 